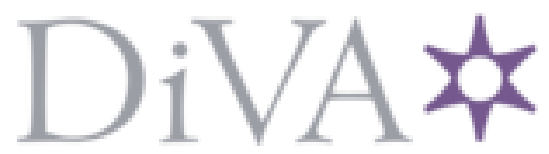

http://www.diva-portal.org

This is the published version of a paper published in The Behavioral Development Bulletin.

Citation for the original published paper (version of record):

Sjölander, P., Lindström, N., Ericsson, A., Kjellström, S. (2014)

A pattern recognition method for disclosing differentlevels of value system from questionnaire data.

The Behavioral Development Bulletin, 19(3): 112-125

Access to the published version may require subscription.

N.B. When citing this work, cite the original published paper.

Open Access journal: http://baojournal.com/BDB WEBSITE/

Permanent link to this version:

http://urn.kb.se/resolve?urn=urn:nbn:se:hj:diva- 12308 


\title{
A pattern recognition method for disclosing different levels of value system from questionnaire data
}

\author{
Per Sjölander1, Nina Lindström2, AnnJessica Ericsson1, and Sofia Kjellström3 \\ 1 Void Institute, Sweden \\ 2 Southern Lapland Research Department, Sweden \\ 3 Jönköping University, Sweden
}

The aim of the present study was to describe, test and validate a method for disclosing significant response patterns from questionnaire data, and for classifying individual response profiles into a sequence of significant patterns. The method is based on pattern recognition statistics and probability calculations. The results from the population tested show that the method can disclose characteristic profiles of different value systems, and that these systems can be arranged in a hierarchical order similar to the conventional levels of ego development. It is suggested that this method is applicable to any multiple choice-questionnaire containing a number of items where the response alternatives represent a sequential order, for example, of different levels of development within a psychological domain. The method might be a valuable tool for acquiring information on the distribution of different levels of adult development in large populations, such as in communities and large organizations.

KEYWORDS: pattern recognition, partial last squares regression, probability calculation, value system, adult development

$\mathrm{K}$ nowledge on the distribution of various levels of adult development in large populations is useful in many contexts, e.g. in reorganization processes and in the planning phase preceding comprehensive interventions in a large organizations, communities, regions or nations. Most existing methods for acquiring data on adult development are not suitable for such applications. Interviews require massive resources in terms of competent staff, time and money when applied on large populations. Another option is to use questionnaires that are relatively inexpensive both to produce and to distribute, but require particular qualities in order to generate representative results. Questionnaires with open-ended questions, such as sentence completion tests, necessitate considerable efforts by the respondents and are therefore likely to deliver poor response rates (Hansell, Ronchi, Sprarcino, \& Stordtbeck, 1985; Truluck \& Courtenay, 2002; Michiel P Westenberg, van Strien,

Author note: Financial support for this project was kindly provided by the European Refugee Fund and the municipality boards of Vilhelmina and Åsele. Correspondence regarding this article should be directed to Dr Per Sjölander, Void Institute, Forsnäs 17, SE-912 90, Vilhelmina, Sweden. Phone numbers: +46 94013 137, +46 730224431. E-mail: per.sjolander@vilhelmina.se
\& Drewes, 2001). Multiple choice-questions, on the other hand, are easy to complete for the respondent and are more likely to generate sufficient response frequencies. A limitation with questionnaires based on pre-formulated response alternatives is that they often cause noisy data that is difficult to deal with by conventional statistical methods.

One way of extracting meaningful information from noisy or complex data is to use multivariate statistics, e.g. principal component analysis. There are several different mathematical varieties of principal component analysis (for review, see Jolliffe 2002). The basic principle of all of them is to make data more interpretable through data reduction and to find latent structures in the data. Some methods are mathematically designed to recognize similarities in response patterns, i.e. pattern recognition methods. The later methods have become common in a wide spectrum of applications, e.g. recognition of speech, faces and finger prints, in diagnostics of tumors and other somatic diseases, and in social science, neuroscience and psychological research (e.g. Johansson et al. 1991; Duda et al 2001; Henningsson et al. 2002; Daerga et al. 2008; Brunelli 2009). In this paper a method called Partial Least Square Regression was used for pattern recognition analysis of value systems. 
Table 1. The relative importance of the 38 variables, shown as variable loadings for the three significant components. The response alternatives of each item have been arranged in a sequential order. For a detailed description of the items and statements, see Appendix 1.

\begin{tabular}{|c|c|c|c|}
\hline \multirow[b]{2}{*}{ Items } & \multicolumn{3}{|c|}{ Component } \\
\hline & 1 & 2 & 3 \\
\hline \multicolumn{4}{|c|}{ B5-responsibility for integration } \\
\hline government and parliament & 0,228 & $-0,101$ & 0,191 \\
\hline national authorities & 0,241 & $-0,063$ & 0,246 \\
\hline local authorities & 0,261 & $-0,143$ & 0,155 \\
\hline non-profit organizations & 0,255 & $-0,111$ & 0,025 \\
\hline all Swedish citizens & 0,277 & $-0,156$ & 0,053 \\
\hline my own & 0,281 & $-0,181$ & 0,017 \\
\hline the refugees & 0,154 & 0,059 & 0,168 \\
\hline \multicolumn{4}{|l|}{ C1-affinity } \\
\hline my family & 0,144 & 0,168 & 0,155 \\
\hline my friends & 0,159 & 0,209 & 0,226 \\
\hline groups I share interests with & 0,122 & 0,222 & 0,108 \\
\hline co-workers & 0,110 & 0,262 & 0,120 \\
\hline local inhabitants & 0,157 & 0,335 & 0,027 \\
\hline Swedes & 0,114 & 0,314 & $-0,015$ \\
\hline Europeans & 0,182 & 0,195 & 0,053 \\
\hline all human beings & 0,219 & 0,198 & $-0,073$ \\
\hline refugees & 0,282 & $-0,022$ & $-0,087$ \\
\hline \multicolumn{4}{|l|}{ C2-important } \\
\hline satisfy my needs & $-0,154$ & $-0,050$ & 0,237 \\
\hline social atmosphere & $-0,034$ & $-0,105$ & 0,159 \\
\hline occupational skills & $-0,112$ & 0,151 & 0,134 \\
\hline develop others people & 0,016 & 0,154 & $-0,340$ \\
\hline develop myself & 0,200 & $-0,037$ & $-0,250$ \\
\hline \multicolumn{4}{|l|}{ C3-good boss } \\
\hline natural authority & $-0,209$ & 0,030 & $-0,014$ \\
\hline social atmosphere & 0,038 & 0,057 & 0,091 \\
\hline expert competency & $-0,091$ & 0,075 & $-0,036$ \\
\hline focused on achievements & $-0,096$ & 0,167 & $-0,132$ \\
\hline all co-workers are individuals & 0,097 & $-0,082$ & 0,008 \\
\hline social and global goals & 0,118 & $-0,021$ & $-0,133$ \\
\hline \multicolumn{4}{|l|}{ C4-law and regulation } \\
\hline difficult to satisfy my needs & $-0,075$ & $-0,050$ & $-0,086$ \\
\hline followed without exception & $-0,064$ & 0,327 & 0,020 \\
\hline to obtain a fair society & 0,022 & 0,279 & 0,081 \\
\hline needs of the individual & 0,100 & $-0,201$ & 0,078 \\
\hline principally based & 0,011 & $-0,224$ & $-0,099$ \\
\hline \multicolumn{4}{|l|}{ C5-thinking about } \\
\hline satisfy my needs & $-0,192$ & 0,006 & 0,255 \\
\hline socially accepted & $-0,117$ & $-0,042$ & 0,190 \\
\hline occupational skills & $-0,042$ & 0,000 & 0,215 \\
\hline efficiency and productivity & $-0,032$ & 0,140 & $-0,258$ \\
\hline tolerant society & 0,218 & $-0,064$ & $-0,287$ \\
\hline saving the mankind & 0,147 & 0,072 & $-0,283$ \\
\hline
\end{tabular}

The aim of the present study was to use pattern recognition statistics to disclose characteristic response patterns in data generated by a multiple choice-questionnaire on psychological value systems, and to use probability calculations to categorize individual responses obtained from a random sample of adult. The characteristic response patterns were hierarchically arranged based on values that have been found to be common in different stages of ego development. The hierarchically arranged categories of value systems were validated by comparison with the Washington University Sentence Completion Test (ego development) and the Hierarchical Complexity Scoring System (complexity of reasoning).

\section{" METHODS}

The questionnaire

A questionnaire was constructed with the main aim to get information on views and attitudes on refugees, discrimination and the Swedish migration policy. This was a part of a larger evaluation of the refugee receptions in two Swedish municipalities.

To enable comparisons between people's views on refugees, discrimination and their general values systems, 6 out of a total of 21 questionnaire items were constructed to gain information on value system (Appendix 1). Our intention was to compose a number of issues and statements with the potential of discriminating between different conventional value systems. The response alternatives and the statements were selected to represent a sequence of values systems, ranging from pre-conventional or early conventional to late conventional or early post-conventional, that we believed should be differently appealing to various conventional levels of adult development. In the questionnaire these response alternatives and the statements were presented in a random order (Appendix 1).

The selection of items and statements were inspired by theories and empirical data presented by Cook-Greuter (1999), Loevinger and Blasi (1976), Loevinger \& Hy (1996), Torbert (2004), and Westenberg et al. (1998), and selected and formulated to fit into the collective norm system of the Swedish society (e.g. distribution of responsibility, "glorification" of labor skills, work efficiency and expertise, and justice through equal opportunities). Three of the 6 questions dealt with rather general issues, i.e. affinity with different groups of people, issues regarded as personally important, and issues one often thought about, whereas three questions were linked to more specific topics, i.e. responsibility for integration of refugees, characteristics of a good boss and views on laws and regulations. For two of the questions the respondents were asked to grade, on an ordinal scale from 1 to 5 , how much responsibility different authorities and groups have for integration of refugees, and how much affinity one feels for different groups of people. The instruction for the other four items was to rank 5-6 statements in accordance with how well or poorly the statements corresponded with the respondent's views and opinions. If none of the pre-formulated statements matched their most preferable view they were encouraged to formulate such a statement on the questionnaire (Appendix 1).

A total of 38 variables were derived from the 6 items and their concomitant response alternatives and statements (see Appendix 1). 
The analyses

To identify prevalent response profiles among those who answer the questionnaire, i.e. to disclose distinct patterns of covariation over the 38 variables, pattern recognition statistics were applied. Partial Last Squares Regression (PLS), which is a type of principal component analysis, was selected since this method is relatively insensitive to multicollinearity in the data (Wold et al. 2001). In contrasts to conventional correlation statistics, PLS account for both linear and non-linear covariation between variables. In PLS the data table is represented as a swarm of points in a multidimentional space where the data points correspond to the individuals' response profiles in a coordinate system with as many axes as there are variables. A vector is fitted to the data swarm, by a least-square method that identifies the direction with the largest variation. Each data point is projected down on this line to create the individual scores of the first principal component (PC1). Based on the residual matrix a second vector, orthogonal to the first, is fitted to the data swarm, again to represent the direction with the largest variation. The projections on this second component (PC2) account for as much of the remaining variability as possible. This procedure can be repeated until the residuals are zero, but usually only the first few components are significant. The first PCs can be seen as uncorrelated variables that represent the most frequent response profiles in the data set.

The PLS also provides values of the so-called loading vectors, showing how the variables are combined to form the distribution of scores (individual response profiles). The relative weight of the individual variables on a PC is called variable loading. Some variables are more important than others. High positive and negative loading values indicate large importance on the distribution of scores (response profiles) whereas values close to zero indicate variables with marginal impact (see Table 1 ).

Before the PLS was commenced, the variables were scaled to unit variance by calculating the scaling weights as $1 / \mathrm{sD} i$, where $\mathrm{SD} i$ is the standard deviation of variable $i$ over the objects. The statistical significance of the PCs was calculated by a cross validation method (Wold, 1978; Eastment \& Krzanowski, 1982). In short, this technique implies that data of the matrix are pseudo-randomly selected and deleted, where after the incomplete matrix is used to calculate a PC. From this PC, the values from the deleted data are predicted. The matrix is then restored and new data randomly selected and deleted. This procedure is repeated until each data element has been deleted once and only once. The sum of the squared differences between the actual and the predicted values are taken as a measure of how adequately the PC predicts the data.

In the present study significant PCs reflect distinct response patterns common in the cross-section population, and it was assumed that these response profiles would correspond to different value systems. To estimate the correspondence between the individuals' response profile and the general response patterns disclosed by the PCs, probability scores were calculated. Thus, the three significant PCs of the first model generated three probability scores for each individual.

The probability score in relation to a given PC was calculated as follows. First the questionnaire score was multiplied, separately for each of the 38 variables (scoreQ1 ...score $Q_{3} 8$ ), with the loading values of the corresponding variables (load $V_{1} \ldots$ load $\left.V_{3} 8\right)$. Thereby the questionnaire scores were scaled to the general response pattern disclosed by the PC. Then the sum of the scaled questionnaire scores was calculated (sumPC1).

$$
\text { sumPC1 } 1=\sum_{i=1}^{38} \text { scoreQ }_{i} \times \operatorname{loadV}_{i}
$$

By relating the sumPC1 to the theoretical maximum and minimum of the scaled sum score for this particular component, a probability value ranging between $\mathrm{o}$ and 1 was obtained (probPC1).

$$
\operatorname{probPC}_{1}=\frac{\operatorname{sumPC}_{1}}{\text { sumPC }_{\max }-\operatorname{sumPC}_{1} \text { min }}
$$

This procedure was repeated for each of the significant components, thus showing the probabilities for an individual response profile to correspond with the significant profiles disclosed by the PLs. The classification of an individual's response profile, i.e. whether it showed the closes correspondence with the significant response profile identified by $\mathrm{PC} 1, \mathrm{PC} 2$ or $\mathrm{PC} 3$, was based on the largest probability value.

\section{The population tested}

The questionnaire was sent to a randomly selected adult population of 600 inhabitants of the municipalities of Vilhelmina and Åsele. These sparsely populated municipalities, located in the northwest of Sweden, hold populations characterized, in a national context, by a relatively low level of education, high unemployment rate and relatively large frequencies of blue collar workers.

After one reminder a total of 281 questionnaires were returned (response rate $47 \%$ ). The gender and age distributions were rather even in the sample of returned questionnaires, i.e. $53 \%$ women (mean age, 54 years) and $46 \%$ men (mean age, 49 years).

Twenty-two of the questionnaires were too incompletely answered to be useful in the analyses. Another 32 did not satisfy the instructions on the ranking-questions, i.e. their responses were undifferentiated, or both incomplete and undifferentiated. For 27 of these at least 2 of the statements were ranked on 3 out of the 4 ranking-questions which eventually made them classifiable based on the general response profiles identified in the PLSs (see Figure 4). Thus, the PLSs were based on a sample of 227 acceptably completed questionnaires, whereas the sociodemographic characteristics of the different classes of value systems were compiled from 254 individuals.

The principal value systems identified through the PCs were sequentially ordered based on theories and empirical data presented by Cook-Greuter (1999), Loevinger \& Blasi (1976), Loevinger \& Hy (1996), Torbert (2004), and Westenberg et al. (1998).

\section{Validation}

To investigate to what extent the sequence of different value systems was related to other psychological domains of adult development, sub-groups of the study population were tested regarding their level of ego development and complexity of reasoning. 
Ego development was assessed with the Washington University Sentence Completion Test (wusct). A Swedish translation of a 18-item version of the wUSCT was used (Rosén, 1997). The form was administrated to a sub-sample of the population $(n=20)$. The response to each item was assigned a score between 1 and 10, and, for each individual, the total protocol rating was obtained through the automatic ogive rules (Loevinger \& Hy, 1996). In accordance with the well established procedures, the scoring was made by one of the author (sK) who is an experienced scorer of wUSCT.

The value system questionnaire was constructed to permit inclusion of response alternatives and statements formulate by the respondents themselves. They were also encouraged to provide written feedback and comments on a separate page added to the questionnaire. Out of the 281 individuals who returned the questionnaire, 112 had included a new response alternative and/or statement and/or provided feedback and/or general comments. For a total of 47 individuals these written statements and comments were sufficiently extensive to permit analyses of the complexity of reasoning. The Hierarchical Complexity Scoring System (HCSs) was used to score the complexity of these statements and comments (Commons et al., 2007). The scoring, which was based on the highest level of reasoning shown by each individual, was done independently by two of the authors (PS and AE). Their indepen-

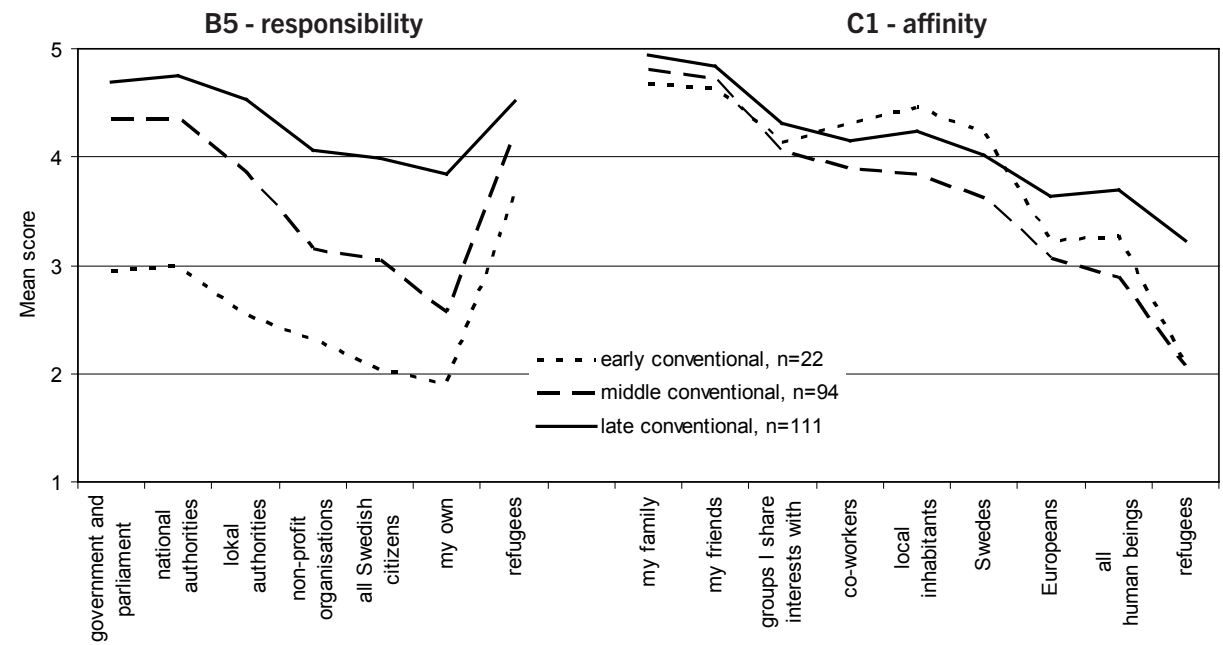

dent ratings were identical for 42 of the individuals (inter-rater reliability $=0.89$ ). After discussions they reached consensus for three, but not for two of the individuals. For the latter two, the highest scores were used in the analyses.

\section{Statistical tools}

Calculations of mean values, correlation coefficients (Spearman's rho, 2-tailed) and statistical significance of bivariate comparisons were performed with sPss (version 11.5, sPSs Inc., USA). A multivariate program package was used for the PLS (SIMCA-P, version 11.o Umetrics, Sweden).

\section{" RESULTS}

\section{Partial last squares regression}

The PLS of the 38 value-related items for the 227 individuals showed three statistically significant principal components, indicating three different response patterns. The model explained $33 \%$ of the variance in the data $-16.6 \%$ of the variance was explained by the first component, $9.1 \%$ by the second and $7.4 \%$ by the third.

The first component was defined by response profiles characterized by high scores on nearly all of the responsibility alternatives and by strong affinity with all people, including refugees, Europeans and all people (Table 1). Moreover, they ranked the following statements high: "it is important to meet other people in order to develop ones ability to critically scrutinize oneself and the norms of the society" (item C2), "a good boss should have long-term, social, humanistic and global visions (item $\mathrm{C}_{3}$ ), "laws should take into consideration the conditions and needs of the individuals" (item $\mathrm{C}_{4}$ ), and "how to achieve a more tolerant society" (item $\mathrm{C}_{5}$ ). These response profiles were also shaped by relatively low ranks of the statements focusing on self-satisfaction and social acceptance on items $\mathrm{C}_{2}-\mathrm{C}_{5}$.

Figure 1. Averaged response profiles for individuals classified with early, middle and late conventional value systems based on the PLS-model and probability calculations.

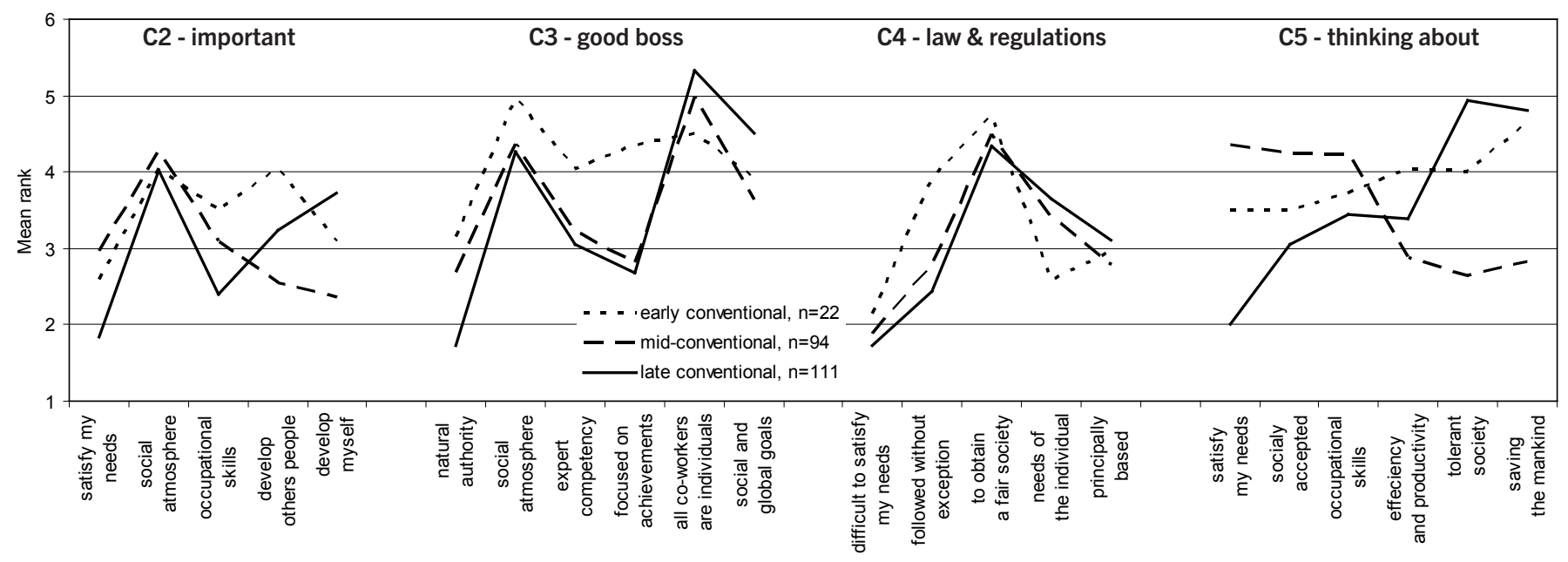


Table 2. Sociodemographic characteristics and responses on two questions on refugees for the sub-groups classified according to value system.

\begin{tabular}{|c|c|c|c|c|c|c|c|c|c|c|c|c|}
\hline \multirow[b]{3}{*}{ Sociodemogaphy } & \multirow{2}{*}{\multicolumn{2}{|c|}{$\begin{array}{c}\begin{array}{c}\text { Early } \\
\text { conventional }\end{array} \\
n=37\end{array}$}} & \multicolumn{4}{|c|}{ Middle conventional } & \multicolumn{6}{|c|}{ Late conventional } \\
\hline & & & \multicolumn{2}{|c|}{$\begin{array}{l}\text { Sub-group } 2 \\
n=25\end{array}$} & \multicolumn{2}{|c|}{$\begin{array}{l}\text { Sub-group } 1 \\
n=76\end{array}$} & \multicolumn{2}{|c|}{$\begin{array}{c}\text { Sub-group } 2 \\
n=12\end{array}$} & \multicolumn{2}{|c|}{$\begin{array}{l}\text { Sub-group } 1 \\
n=89\end{array}$} & \multicolumn{2}{|c|}{$\begin{array}{c}\text { Sub-group } 3 \\
\quad n=15\end{array}$} \\
\hline & Women & Men & Women & Men & Women & Men & Women & Men & Women & Men & Women & Men \\
\hline Gender distribution & $14 \%$ & $16 \%$ & $7 \%$ & $12 \%$ & $30 \%$ & $30 \%$ & $2 \%$ & $7 \%$ & $40 \%$ & $30 \%$ & $7 \%$ & $5 \%$ \\
\hline Mean age, years & 68 & 49 & 33 & 42 & 44 & 44 & 75 & 39 & 52 & 56 & 61 & 60 \\
\hline \multicolumn{13}{|l|}{ Highest level of education } \\
\hline I) compulsory, 6-9 years & $55 \%$ & $17 \%$ & $10 \%$ & $27 \%$ & $10 \%$ & $22 \%$ & $67 \%$ & $22 \%$ & $9 \%$ & $26 \%$ & $45 \%$ & $50 \%$ \\
\hline ॥ college, $10-12$ years & $28 \%$ & $71 \%$ & $80 \%$ & $40 \%$ & $58 \%$ & $51 \%$ & $0 \%$ & $67 \%$ & $54 \%$ & $46 \%$ & $33 \%$ & $33 \%$ \\
\hline ॥) university, >13 years & $17 \%$ & $12 \%$ & $10 \%$ & $33 \%$ & $32 \%$ & $27 \%$ & $33 \%$ & $11 \%$ & $37 \%$ & $29 \%$ & $22 \%$ & $17 \%$ \\
\hline \multicolumn{13}{|l|}{ Occupation } \\
\hline » working & $17 \%$ & $57 \%$ & $55 \%$ & $69 \%$ & $62 \%$ & $82 \%$ & $33 \%$ & $56 \%$ & $61 \%$ & $72 \%$ & $46 \%$ & $50 \%$ \\
\hline ॥ retired & $72 \%$ & $24 \%$ & $9 \%$ & $19 \%$ & $19 \%$ & $15 \%$ & $67 \%$ & $33 \%$ & $25 \%$ & $21 \%$ & $45 \%$ & $33 \%$ \\
\hline » sick leave, unemployed & $11 \%$ & $10 \%$ & $18 \%$ & $6 \%$ & $10 \%$ & $0 \%$ & $0 \%$ & $0 \%$ & $3 \%$ & $5 \%$ & $0 \%$ & $0 \%$ \\
\hline ») studying & $0 \%$ & $9 \%$ & $18 \%$ & $6 \%$ & $9 \%$ & $3 \%$ & $0 \%$ & $11 \%$ & $11 \%$ & $2 \%$ & $9 \%$ & $17 \%$ \\
\hline \multicolumn{13}{|l|}{ Questions on refugees } \\
\hline \multicolumn{13}{|l|}{$\begin{array}{l}\text { What is your view on } \\
\text { the fact that Sweden } \\
\text { accepts refugees?* }\end{array}$} \\
\hline Very positive & $14 \%$ & $8 \%$ & $20 \%$ & $7 \%$ & $15 \%$ & $9 \%$ & $33 \%$ & $50 \%$ & $35 \%$ & $15 \%$ & $38 \%$ & $50 \%$ \\
\hline Very negative & $43 \%$ & $31 \%$ & $10 \%$ & $7 \%$ & $0 \%$ & $3 \%$ & $0 \%$ & $17 \%$ & $0 \%$ & $0 \%$ & $0 \%$ & $0 \%$ \\
\hline \multicolumn{13}{|l|}{$\begin{array}{l}\text { Are refugees discriminated } \\
\text { in Sweden? }\end{array}$} \\
\hline Yes & $0 \%$ & $17 \%$ & $50 \%$ & $53 \%$ & $46 \%$ & $50 \%$ & $67 \%$ & $67 \%$ & $58 \%$ & $56 \%$ & $75 \%$ & $60 \%$ \\
\hline No & $53 \%$ & $61 \%$ & $20 \%$ & $13 \%$ & $31 \%$ & $17 \%$ & $33 \%$ & $11 \%$ & $9 \%$ & $29 \%$ & $13 \%$ & $20 \%$ \\
\hline Don't know & $47 \%$ & $22 \%$ & $30 \%$ & $33 \%$ & $23 \%$ & $33 \%$ & $0 \%$ & $22 \%$ & $33 \%$ & $15 \%$ & $13 \%$ & $20 \%$ \\
\hline
\end{tabular}

* the response alternatives were given as a 5-graded ordinal scale, from 'very positive' (5) to 'very negative' (1)

The response profiles that shaped the second component were dominated by low scores on the responsibility alternatives, particularly "my own", and by strong affinity with "co-workers", "local inhabitants" and "Swedes", and weak affinity with "refugees" (Table 1). Among the ranking issues, this component was characterized by high ranking of the statements "value my expert competencies and occupational skills" and "developing other people to increase productivity and economic growth" (item $\mathrm{C}_{2}$ ), "a good boss should be focused on achievements and economic growth" (item $\mathrm{C}_{3}$ ), "laws and regulations should be followed without exceptions" and "laws and regulations are needed to obtain a fair society" (item $\mathrm{C}_{4}$ ), and "how to create more effective and productive companies and social structures" (item $\mathrm{C}_{5}$ ). This component was also formed by disagreement with "laws and regulations should consider the conditions and needs of the individuals" (item $\mathrm{C}_{4}$ ), and "laws and regulations could always be questioned, except those based on fundamental principles" (item $\mathrm{C}_{4}$ ).

The third significant component was dominated by response profiles claiming that the national authorities and the refugees should take large responsibilities for integration (Table 1). The affinity was strongest with family and friends, and weakest with "all human beings" and refugees. Among these profiles the statements focusing on self-satisfaction, social atmosphere and occupational skills, were highly ranked (items $\mathrm{C}_{2}$ and $\mathrm{C}_{5}$ ). Low rankings were given to the statements "contribute to developing other people in order to increase productivity and economic growth" and "to meet people with other values who develop my ability to critically scrutinize myself and the norms of society" (item $\mathrm{C}_{2}$ ). Other low ranked alternatives were "how to achieve a more tolerant society where all people and cultures are respected", "how mankind can be saved from global pollution, starvation and oppression" and "how to create more effective and productive companies and social structures" (item $\mathrm{C}_{5}$ ).

\section{Classification of the test population}

The classification procedure, i.e. the comparison of the probability values of the individual response profiles, demonstrated that 111 showed the best correspondence with the profile defined by the first principal component, 22 individual profiles with the second component, and 94 individual profiles with the third component.

As deemed from the average response profiles shown in Figure 1 , the three groups seem to reflect differently developed value systems. The group with profiles corresponding to the first component appears to be more developed than the other two groups. These individuals indicate larger personal responsibility for integration, stronger affinity with people in general, lower "inclination/need" for self-satisfaction, deeper awareness of individuality, tolerance and personal development. This group seems to correspond to 
Table 3. Comparison of classifications according to the ego development (WUSCT) and the value system.

\begin{tabular}{llllll}
\hline Value system & Stage & $\boldsymbol{N}$ & WSCT & Stage & $\boldsymbol{N}$ \\
\hline Early conventional & 4 & 1 & Conformist & 4 & 3 \\
\hline $\begin{array}{c}\text { Middle conventional } \\
\quad \text { Sub-groups 1 \& 2 }\end{array}$ & 5 & 1 & Self aware & 5 & 4 \\
\hline Late conventional & & & & & \\
$\quad$ Sub-groups 1 \& 2 & 6 & 14 & Conscientious & 6 & 10 \\
Sub-groups 3 & 7 & 4 & Individualist & 7 & 3 \\
\hline
\end{tabular}

late conventional or early post-conventional value systems, as described by others (Cook-Greuter, 1999; Loevinger \& Blasi, 1976; Torbert, 2004), and is hereby denoted late conventional.

The other two groups demonstrate common characteristic in comparatively low personal responsibility for integration and poor feeling of affinity with people outside Sweden (particularly with "intruders" like refugees), and regard social acceptance and security as more important than individuality (Figure 1). But there are also some striking differences between there two groups. The group with profiles corresponding to the second component indicates very low responsibility scores for all authorities, Swedes and themselves, but not for the refugees who, by far, holds the largest

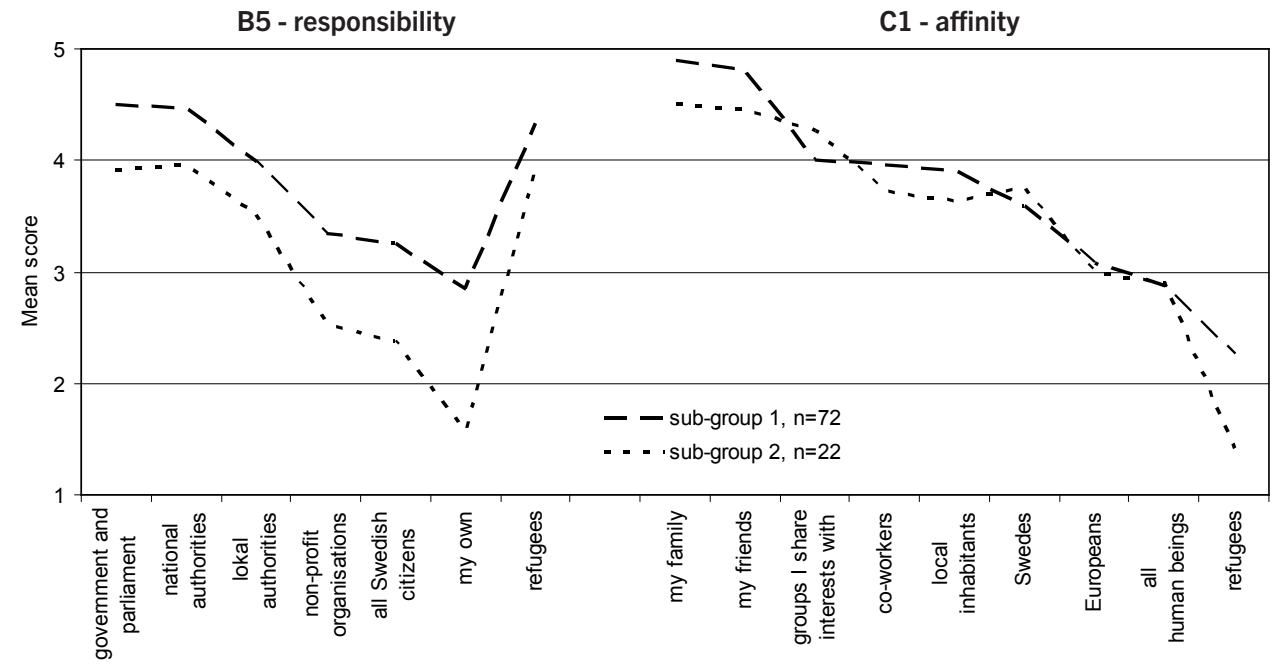

responsibility for their integration. They show strong beliefs in leaders who are "natural" authorities, and they hold the opinion that laws and norms should be followed without exceptions. They demonstrate the most nationalistic affinity pattern and eco the Swedish norm of glorifying expert skills, efficiency and productivity. The value system of this population seems to be largely in conformity with the collective norm system, as described by others (Cook-Greuter, 1999; Loevinger \& Blasi, 1976; Torbert, 2004), and is hereby denoted early conventional.

The third group, which corresponds mostly with the third principal component, deviates significantly from the other two groups in some distinct ways. Their profile indicate the greatest need for self-satisfaction, the most frequent thoughts on how once occupational skills might be improved, in combination with the weakest understanding of the need for developing others, developing oneself, creating a tolerant society, and managing global social and environmental problems (Figure 1). This group seems to match the self-consciousness level of development, as described by others (Cook-Greuter, 1999; Loevinger \& Blasi, 1976; Torbert, 2004), and is hereby denoted middle conventional.

To explore whether these three populations could be further separated into sub-groups with more specific characteristics, a new PLS was run on each of these. The analysis of the early conventional-group produced one significant principal component only. However, the middle conventional-group was split up into two separate groups as judged from the PLS and the probability calculation. The PLS-model explained a total of $21.4 \%$ of the variance of the data (12.4\% and $9.0 \%$ explained variance for the two components). Most of the individual response profiles showed a higher probability to fit with the first component $(n=72)$, while a smaller sub-group matched the pattern exposed in the second component $(n=22)$.

Figure 2. Averaged response profiles for subgroups with middle conventional value systems.

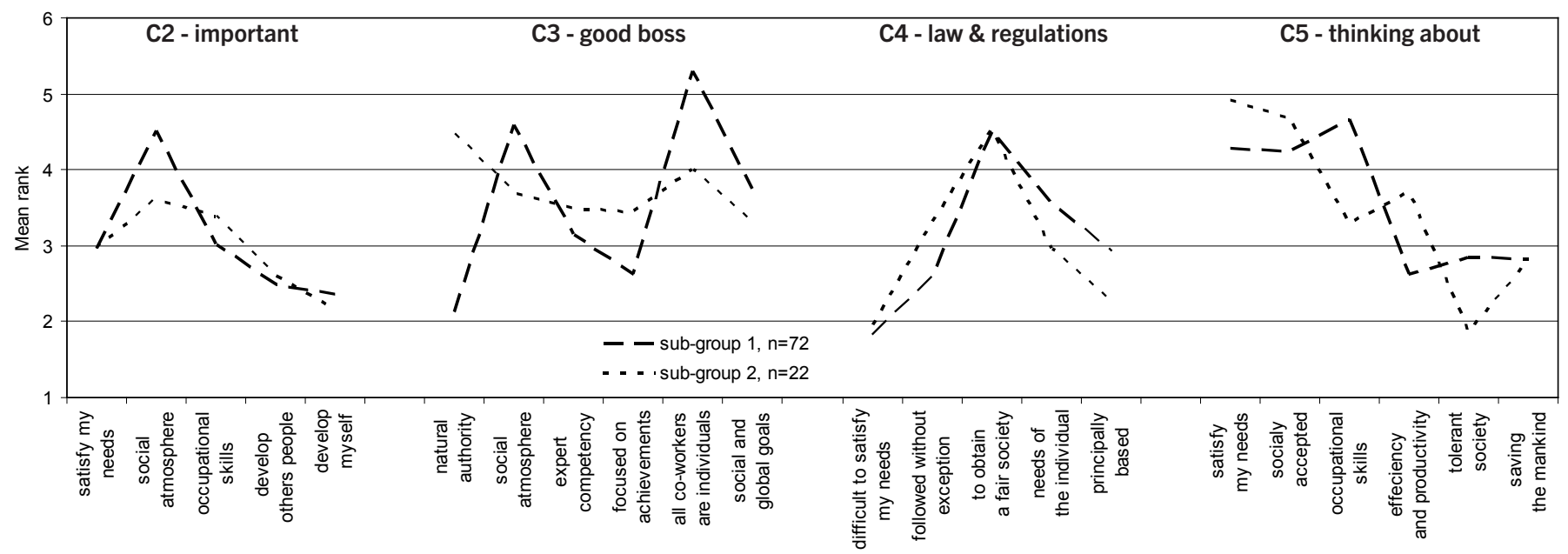


The response profile of the larger mid-conventional sub-group confirms essentially with the characteristics described above (cf. Figure 1 and 2). However, the smaller sub-group showed some clearly deviating features. Overall this sub-group scored lower on the "occupational skill"-alternatives as compared with the other middle convetionals. The scores on the responsibility issues were generally lower, and particularly low for their own responsibility, the responsibility of non-profitable organizations and all Swedish citizens (Figure 2). Their affinity with refugees was weaker, and they regarded the social atmosphere as less important. The response profile on the good boss-issue was rather similar to that of the early conventional group except for higher scores on the natural authority-statement and somewhat lower rankings of the other alternatives. The profile on the law and regulation-issue was also more similar to that of the early conventional with the exception that scored lower on the statements "without exception" and "principally based". Their thoughts were most often directed towards self-satisfaction and to be socially accepted, while the statement "tolerant society" exhibited the lowest ranking. This sub-group could be in transition from an early to a mid-conventional value system.

The PLS on the late conventional group resulted in three significant principal components.

The model explained a total of $28.8 \%$ of the variance of the data $(11.9 \%, 8.6 \%$ and $8.3 \%$ explained variance for the three

Figure 3. Averaged response profiles for subgroups with late conventional value systems.

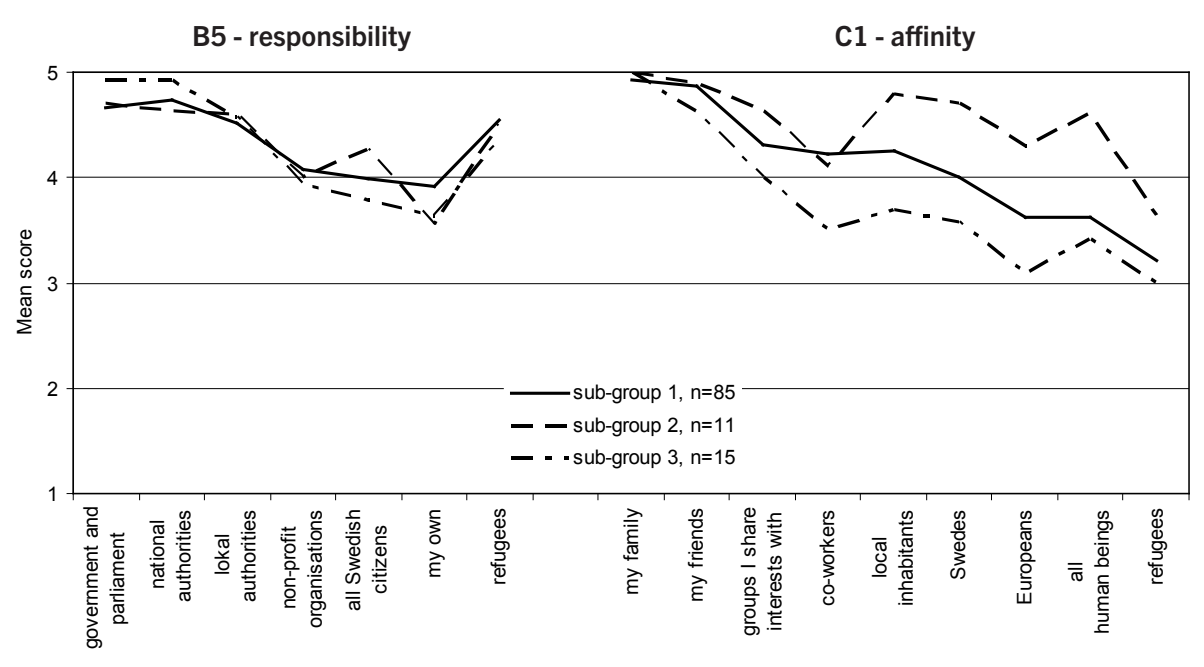

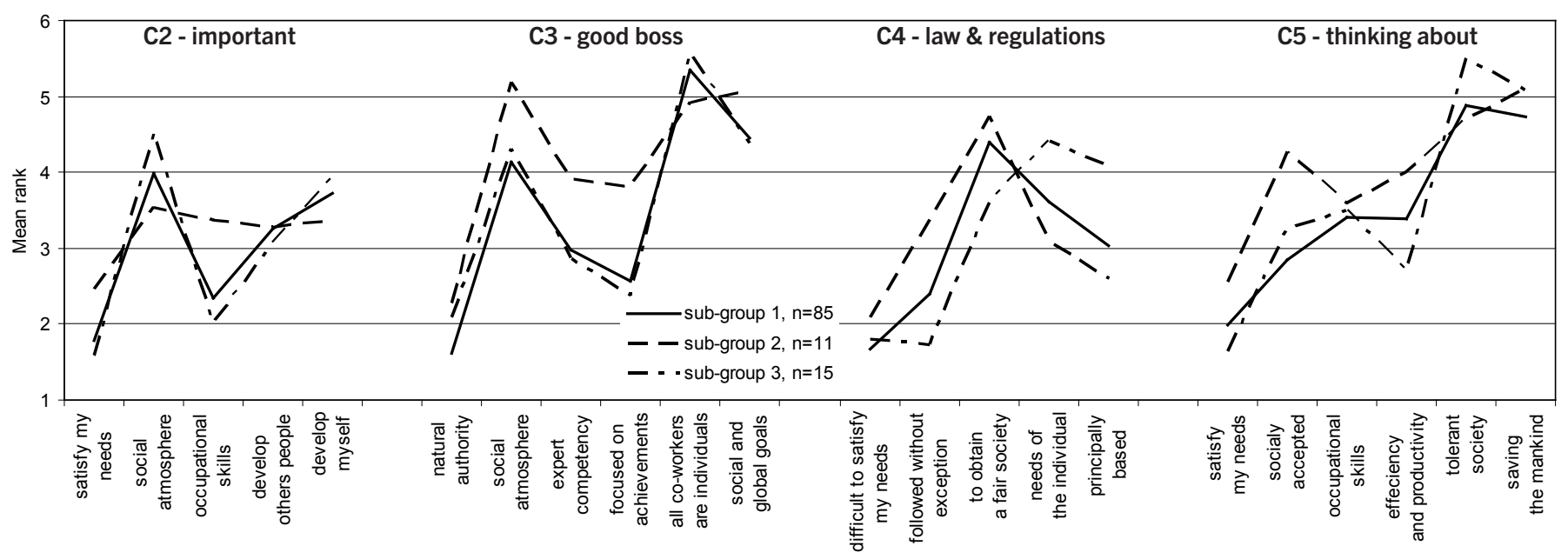




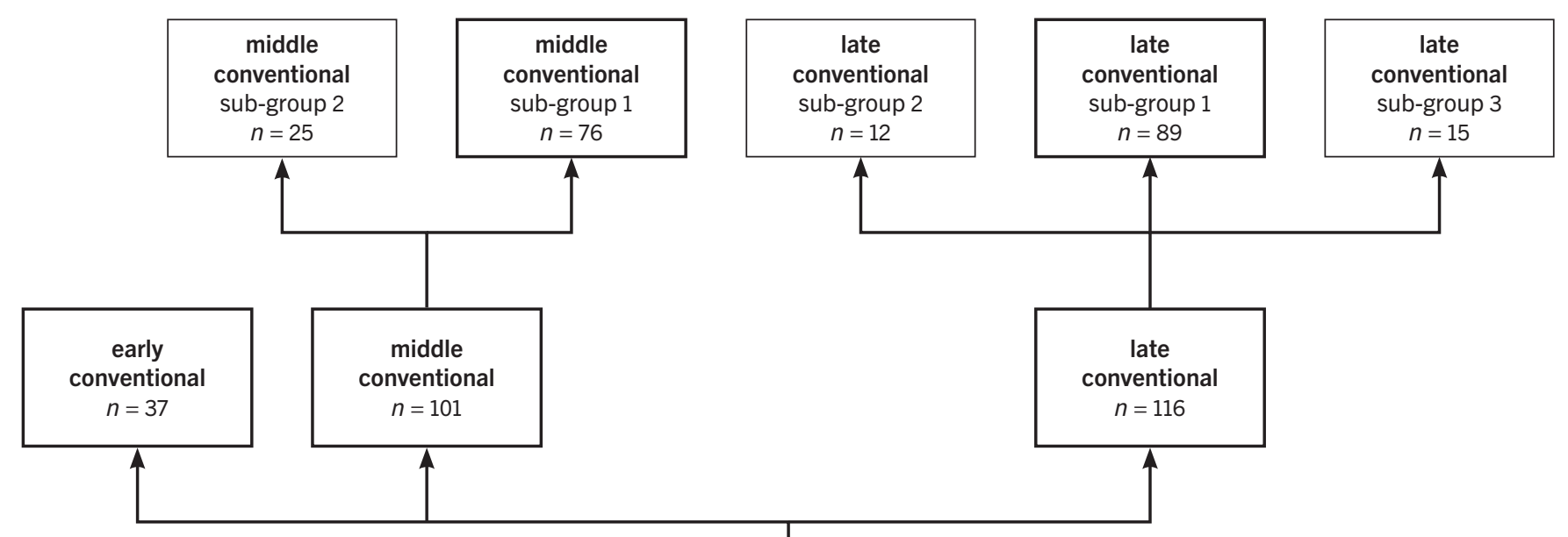

similar to the middle conventional, except that they demonstrated higher responsibility and affinity scores (sub-group 2, Figure 3). They demonstrated higher scores in comparison with the main group of late conventional profiles on most of the statements concerning social atmosphere, occupational skills, efficiency and productivity. These profiles were also characterized by lower ranking of the individualistic alternatives. It seems reasonably to conclude that this sub-group contains individuals with value systems in-between the mid-and the late conventional value systems.

The third of the late conventional sub-groups showed response profiles with some distinct differences compared with the other sub-groups (sub-group 3, Figure 3). These individuals reported higher ratings on the individualistic alternatives on the "law and regulation" and on the "thinking about" issues. Their scores on the "saving the mankind" and "principally based laws" statements were also higher than the other sub-groups'. Moreover, they ranked "followed without exceptions", "to obtain a fair society" and "efficiency and productivity" alternatives lower than the other sub-groups. Their response profiles may indicate that this sub-group was composed of individuals in the border between late conventional and early post-conventional stages of value systems.

Based on the response profiles of the 6 identified groups it was possible to classify 27 of the 32 individuals who had provided too undiversified answers to be included in the PLS (see Methods). Fifteen of these were classified as having value systems typical for the early conventional group, 3 as mid-conventional subgroup 2 value systems, 4 as mid-conventional sub-group 1 value systems, 1 as late conventional sub-group 2 value system, and 4 as late conventional sub-group 1 value systems. Thus, a total of 254 individual were classified into a sequence of 6 different value systems (Figure 4).

Table 2 shows some sociodemographic data for the 6 subgroups, together with their response characteristics on two of the refugee questions. There were no significant relations between the sequence of value systems, the gender distribution, the mean age, the level of education and the occupations, as deemed from non-significant bivariate correlations $(\mathrm{p}>0.05)$. However, the

test population $n=281$
Figure 4. The distribution of individuals over the 6 groups of value systems disclosed by the PLS-models and probability calculations
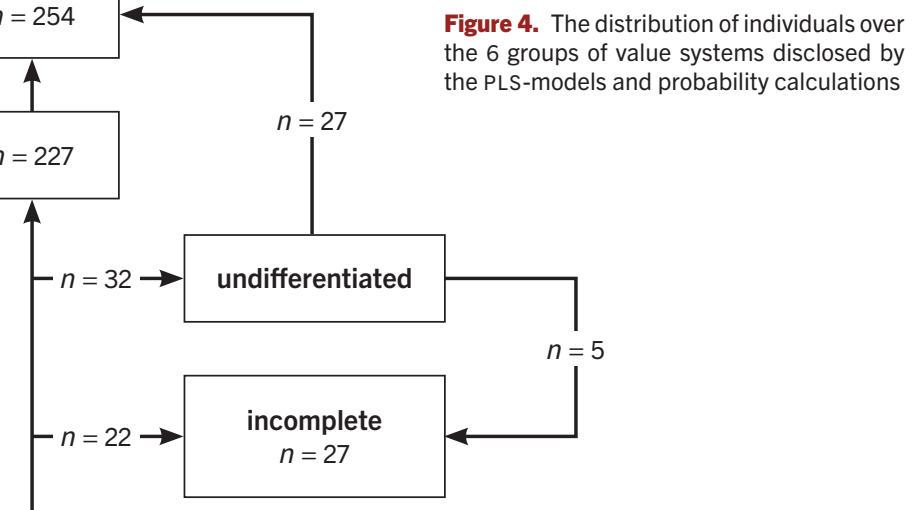

views on refugees showed clear-cut relations with the value systems. The sub-groups representing the more developed value systems were significantly more positive towards refugees in comparison with the sub-groups with less developed value systems (Table 2). The same trend was observed for the question on discrimination of refugees where the more developed value systems were associated with a higher frequency of recognition of discrimination whereas the less developed value systems showed a higher frequency of rejection of discrimination. For both these questions the responses were significantly correlated with the value systems (coefficients $=0.361$ and 0.278 , respectively; $\mathrm{p}<0.001$ for both).

\section{Comparison of the value results with WUSCT and HCSS}

A small group of the test population completed both the questionnaire and the 18-item wUSCT. To construct compatible classification scales, the 6 sub-groups identified by the questionnaire were ranked on the same ordinal scale as used for ego development (Table 3).

The classification scores obtained for value system and for ego development were significantly correlated $(r=0.536 ; p=0.015)$. A perfect match between the two scoring systems was found for 11 out of the 20 individuals. In 6 cases the score on value system was one stage higher than that for ego development, while in two cases the score on value system was one stage lower. For one individual the score on value system was two stages higher than that for ego development. 
The scores on ego development were not significantly correlated with age $(r=0.331 ; p=0.154)$, level of education $(r=0.151 ; p=0.525)$, attitude towards refugees (see Table $2 ; r=0.265 ; p=0.259$ ), nor on the discrimination question (see Table 2; $r=0.256 ; p=0.289$ ).

A comparison of the stage of reasoning and the value systems for 47 individuals is shown in Table 4 . The complexity ranged from concrete to meta-systematic, and the large majority of the individuals scored as formal (Table 4). However, the scores on the HCSS were not correlated with the value systems $(r=0.034$; $p=0.825)$, neither with age $(r=0.066 ; p=0.665)$ nor with the questions on attitude towards refugees and on discrimination (see Table 2; $r=0.226$ and $0.169 ; p=0.136$ and 0.267 respectively), but significantly with level of education $(r=0.353 ; p=0.016)$.

\section{" DISCUSSION}

This paper presents a method for disclosing value systems from questionnaires with pre-formulated response alternatives. The method is based on pattern recognition statistics and probability calculations that are applicable to any questionnaire containing a number of items where the response alternatives represent a sequential order e.g. of different levels of development within a psychological domain. The results from the population tested show that the method can disclose characteristic profiles of different value systems, and that these systems can be arranged in a hierarchical order similar to the levels of adult development identified through other methods. These methods might be a valuable tool to get information on the distribution of different levels of adult development in large populations, such as in communities and large organizations.

An important advantage with pattern recognition statistics and probability calculations is that this classification procedure is more objective than methods that depend on specifically trained raters or scorers. With the present approach there is no need to construct quantitative or qualitative classification criteria or 'ogive' rules that are bound to be more or less subjective due to e.g. semantic ambiguities, intra-disciplinary prejudices, cultural context, and the individual interpreter's stage of adult development. Partial least square regression identifies relations between all variables in the data, and by using the loading scores of each variable in the classification procedure all variables, but those with zero variance in all patterns, are taken into account. Most other methods applied in studies of adult development focus on one or a few qualitative features characteristic at different stages of development. By grouping the individuals according to the mathematic probability of belonging to identified response patterns the categorization procedure is unaffected by interpretation biases.

A most accurate method of assessing a person's level of psychological development is by talking to him/her, given that you know which questions to ask and that you are at least at the same level of development as the one you are speaking to. Thus, methods based on interviews hold a large potential to gain specific knowledge on various psychological characteristics. This has been evident by studies in a number of psychological domains showing convincing reliability and validity (e.g. King \& Kitchener, 2004; Skoe \& von der Lippe, 2002).
However, interviews are time consuming, expensive and require specific skills that make such techniques unsuitable for data acquisitioning in large surveys. Questionnaires with open-ended items require considerable efforts and cognitive abilities by the respondents. For instance, sentence completion tests are not likely to be completed by individuals who have linguistic dysfunctions. Distribution of sentence completion tests in large populations is destined to deliver poor response rates. Multiple choice-questions often generate larger response frequencies since they are easy to complete. Major drawbacks with this approach are that the outcome will be a direct reflection of the mind-frame of the constructor of the questions and response alternatives, and that the respondents' actual views may not be captured by the pre-formulated response alternatives. This limitation can be reduced by encourage the respondents to complement the response alternatives with own formulations, which was done in the questionnaire developed for the present study.

Another limitation with multiple choice-questionnaires is that they are inclined to generate noisy data with poor internal consistency. This is a considerable problem when the results obtained from single items are important for the study. The pattern recognition method applied in the present study identifies significant response profiles over a number of items, which makes the outcome less sensitive to noise and weak internal consistency. An implication of this approach is that conventional reliability and consistency tests, such as Cronbach's alpha and Rasch analyses, are not suitable to assess the reliability of the results. In PLS the reliability is evaluated through the statistical significance of the PCS and the part of the total variance that are explained by the model. In the PLS-models of the present study, the significant PCs together explained $21-33 \%$ of the total variance of the data. This is not too bad taken into account the large heterogeneity of the individual response profiles. Each individual showed a unique response profile, i.e. there were not two individuals with identical response profiles over the 38 variables. More importantly, more than one significant PC were defined in three out of the four PLS-models, indicating that the data set indeed contains several distinct response patterns with fundamentally different characteristics.

A prerequisite for identification and classification of response profiles through pattern recognition methods and probability calculations is that the questionnaire contains a sufficient number of questions with response alternatives that form a sequential structure. In the questionnaire used in this study the response alternatives and the statements were selected to represent a hierarchical sequence of values systems, ranging from pre-conventional/ early conventional to late conventional/early post-conventional. In the analyses it became clear that some of the statements had poor discriminating power. Thus, the collection of response alternatives was certainly not the most optimal, but nonetheless indicates that the methods used for extraction and classification of response profiles is quite compelling. An exchange of some of the response alternatives in future versions of the questionnaire will probably reduce the noise and improve the discriminating potential.

In general, items where the respondent is forced to rank different statements are more discriminating than items where the response is marked on an ordinal scale (cf. questions $\mathrm{C}_{2}$ - 
$\mathrm{C}_{5}$ and $\mathrm{B}_{5}, \mathrm{C}_{1}$; Appendix 1). However, for some questions the ranking approach is unsuitable. An example is the affinity question (question $\mathrm{C}_{1}$ ) where nearly everyone would have top-ranked 'my family' and 'my closest friends'. These response alternatives cannot of course be omitted since that would have evoked serious doubts among the respondents about the credibility of the questionnaire as a whole. A restraint with the ranking approach is that the respondent requires a certain level of cognitive ability to understand and to complete the ranking task. In the population tested about $11 \%$ provided undifferentiated rankings, mostly by individuals with early conventional value systems (Figure 4), suggesting that the ranking task might be too challenging for individuals with poor capacity to deal with complex issues.

The first PLs disclosed three distinct response patterns that we believe relate to early, middle and late conventional value systems (Figure 1). The hierarchical structuring of these response patterns was based on their correspondence with characteristic features previously described for different conventional levels of ego development and action logic (Cook-Greuter 1999, Loevinger \& Blasi 1976, Loevinger \& Hy 1996, Torbert 2004, Westenberg et al. 1998). The early conventional value system bears resemblance to the diplomat/conformist stage, e.g. emphasizing social acceptance, natural authority, obedience to laws and regulations, echoing social norms such as the importance of occupational skills, efficiency and productivity, and disregarding individuality. The middle conventional value system shows similarities with the expert/self aware level, e.g. stresses self-satisfaction, individuality, social acceptance and occupational skills, but pays week attention to common and global issues, developing a tolerant society and a critical view on oneself and the society. The late conventional value system showed resemblance both to the achiever/conscientious stage and the individualist stage, e.g. pronounced self-responsibility, feeling of affinity with people in general, emphasizing a tolerant society, individuality, own development, global and social goals, relatively low need for self-satisfaction, social acceptance, and occupational skills.

The probability calculations allowed classification of the individual response profiles as predominantly early, middle or late conventional. Separate PLS-models based on these main sub-populations resulted in identification of three characteristic profiles within the late and two within the middle conventional sub-populations (Figure 2 and 3). However, the PLS on the early conventional sub-population produced only a single significant PC, hence indicating a rather homogenous response pattern. The altogether 6 identified response patterns were sequentially ordered, and the probabilities of the individual's response profiles to fit each of these were calculated. The distribution of the individuals over the 6 categories of value systems showed aggregations in the early conventional, in one of the middle and one of the late conventional value systems. In the sequential structure, the three other sub-groups of value systems were located in-between the larger ones, indicating transition stages between and/or sub-groups within the early, middle and late conventional and early post-conventional value systems (Figure 4).
The distribution of the test-population over the three main categories of value systems is in accordance what would be expected, and corresponds reasonably well with the distribution different stages of ego development reported in a mixed population from the USA (Torbert 2004). The relatively larger frequency of late conventional individuals in the present study is probably due to a sample bias. That is, people with late conventional value systems are probably the sub-group in which the response rate is the highest (there is a reason why this level of ego development is called conscientious). In contrast, pre-conventional people are the least likely to participate in any kind of voluntary surveys or study, unless they are offered a personal reward or are threatened to be punished. A contributing factor to the relatively larger group of individuals classified as late conventional is that this group might conceal post-conventional respondents. Although this is quite likely as indicated by the response pattern characteristic for the late conventional sub-group 3, this sub-group was very small (Figure 3). The questionnaire was not designed to identify value systems beyond the early post-conventional level since such individuals are very uncommon and even unique in the part of Sweden where the present survey was done (e.g. lack of companies and authorities that attract such people, local culture that strongly promotes conventional values, continuous emigration of 'unconventional' people etc).

The values hold by a person is a result of norms of the society and psychological properties. Societal norms are supposed to have a larger impact on the individuals' value system at conventional stages of development, particularly at the early stages, than in the post-conventional ones (Loevinger \& Blasi, 1976, Cook-Greuter, 1999). In a psychological perspective the internalized values are influenced by, or the consequence of, a number of qualities such as e.g. the perception of oneself, others people and the world around us, identity and affinity, and cognitive abilities. The preliminary validation measures indicate that the value systems, defined by the selection of items compiled in the present questionnaire, are related to ego development but not to the complexity of reasoning.

The positive correlation observed between value priorities and WUSCT-scores was expected since the questionnaire was constructed to capture characteristic value priorities in different stages of ego development. Yet, the relatively weak correlation coefficient shows that the wUSCT and the value system test are different constructs. A significant association between stages of ego development and value systems has been reported previously (e.g. Helson \& Wink, 1987).

The questions and response alternatives selected to investigate people's value priorities in the present study are to various extent related to three out of the four main domains of ego development; character development, interpersonal style and conscious preoccupations (Loevinger \& Blasi, 1976; Loevinger, 1998). Attempts to include the fourth domain, cognitive style, were deliberately omitted since cognitive capacity is quite unfeasible to conclusively investigate by a questionnaire with pre-formulated response alternatives. This might partly explain the lack of correlation between the value profiles and the HCSs-scores. 
Another potential reason for the absence of relation between the value systems and the HCss-scores might be that the written statements and comments on with we scored complexity of reasoning poorly represented the individual's actual ability to handle complexity (i.e., a statistical type 2 error). The statements and comments covered a wide range of topics and some of the comments were clearly written in an emotional state of mind and perhaps therefore reflected an unrepresentatively low level of complexity. Also, the method of HCss is vulnerable for misclassifications. Scoring the complexity of people's thinking or reasoning is unavoidably influenced by the scorer's presumptions, semantic interpretations and ability to identify different levels of complexity. For instance, a given word, abstraction or concept can be used by people at different stages of adult development, but their understanding and interpretation of it could differ significantly. Different scorer might interpret the logical structure of a given response rather differently, which is evident by the imperfect correlations obtained in inter-rater reliability studies of HCss. To some extent the semantic ambiguity could be coped with by probing for people's actual understanding of a given word, abstraction, logical connection, coordination of systems etc. During interviews this could be done by asking probing questions. However, that is not an option when written statements from questionnaires are analyzed. An implication of this is that the complexity scoring presented in this paper sometimes contained a fair amount of 'reading behind the lines' and intuitive probability estimates. To minimize this bias more than half of the responses were omitted since we deemed them as inconclusive regarding their level of complexity.

A more likely explanation for the absence of a significant relation between value priorities and complexity scores is that cognitive abilities, like the complexity of reasoning, and value systems are developed independently, at least in conventional stages of devel- opment where value priorities largely constitute an echo of norms and values held by the in-group culture (Loevinger \& Blasi, 1976). This suggestion is in agreement with previous studies reporting non-significant relationships between cognitive development and ego development (King et al., 1989; Commons et al., 1989). Within a given stage of complexity, using equally solid lines of arguments and logical connections, different persons might end up at diametrically different value priorities. For example, one might be against immigration since it implies that we have to use considerable societal resources before the immigrants have learned our language, got a job and can make a reasonable contribution to the society, while another might be in support of immigration since it provide the society with new citizens with competencies that are valuable at the labor market. Both are formal lines of augments but end up at completely different value priorities.

In late conventional and post-conventional stages of development, complexity and value scores are more likely to be positively related (Cook-Greuter 1999). This is supported by the observation that the three individuals who demonstrated meta-systematic reasoning in the present study showed late conventional or early post-conventional values profiles.

The poor correspondence between value profiles and the complexity of reasoning might raise doubts about whether value systems can be arranged in a hierarchical structure at all. However, we think that there are good reasons to believe that. The value profiles were positively correlated with the ego development scores and, more importantly, the hierarchically arranged sequence of value profiles conforms to general developmental principles (Sjölander 2013). At later stages of development the individuals were more consistent in their value priorities and in their capacity to differentiate between different values, their ability to coordinate and integrate different values increased, and their autonomy increased in relation to culturally important values.

\section{REFERENCES}

Brunelli, R. (2009). Template matching techniques in computer vision: theory and practice, New York: Wiley.

Commons, M. L., Armon, C., Richards, F. A., \& Schrader, D. E. (1989). A multi-domain study of adult development. In M. L., Commons, J. D., Sinott, F. A., Richards, \& C. Armon (Eds.), Adult Development. Vol 1: Comparisons and applications of developmental models ( $\mathrm{pp}$. 33-56). New York: Praeger.

Commons, M. L., Rodriguez, J. A., Miller, P. M., Ross, S. N., LoCicero, A., Goodheart, E. A., et al. (2007). Applying the model of hierarchical complexity. Unpublished manuscript.

Cook-Greuter, S. R. (1999). Postautonomous ego development: a study of its nature and measurement. Integral Publishers: Dissertation Series.

Daerga. L., Edin-Liljegren. A. \& Sjölander. P. (2008). Quality of life in relations to physical, psychosocial and socio-economic conditions among reindeer-herding Sami. International Journal of Circumpolar Health, 67(1),10-28. doi:10.3402/ijch.v67i1.18223

Dawson, T. L. (2002). A comparision of three developmental stage scoring systems. Journal of Applied Measurement, 3(2), 146-189.

Dawson, T. L. (2003). A stage is a stage is a stage: a direct comparison of two scoring systems. Journal of Genetic Psychology, 164(3), 335-364. doi: 10.1080/00221320309597987
Dawson, T. L. (2004). Assessing intellectual development: three approaches, one sequence. Journal of Adult Development, 11(2), 71-85. doi: 0.1023/B:JADE.0000024541.84265.04

Dawson, T. L. (2006). The meaning and measurement of conceptual development in adulthood. In C. H. Hoare (Ed.), Handbook of adult development and learning (pp. 433-454). Oxford: Oxford University Press.

Dawson, T. L., Xie, Y., \& Wilson, M. (2003). Domain-general and domain-specific developmental assessments: do they measure the same thing? Cognitive Development, 18(1), 61-78. doi: 10.1016/ S0885-2014(02)00162-4

Duda, R. O., Hart P. E., \& Stork D. G. (2001). Pattern classification (2. ed). New York: Wiley.

Eastment, H., \& Krzanowski, W. (1982). Cross validatory choice of the number of components from a principal component analysis. Technometrics, 24(1), 73-77. doi: 10.2307/1267581

Helson, R., \& Wink, P. (1987). Two conceptions of maturity examined in the findings of a longitudinal study. Journal of Personality and Social Psychology, 53(3), 531-541. doi: 10.1037/0022-3514.53.3.531 
Hansell, S., Ronchi, D., Sprarcino, J., \& Stordtbeck, F. L. (1984). Ego Development Responses in Written Questionnires and Telephone Interviews. Journal of Personality and Social Psychology, 47(5), 11181128. doi: 10.1037/0022-3514.47.5.1118

Henningsson, M., Sundbom, E., Armelius, B. A., \& Erdberg, P. (2001). PLS model building: a multivariate approach to personality test data. Scandinavian Journal of Psychology, 42(5), 399-409. doi: $10.1111 / 1467-9450.00252$

Hoare, C. H. (2006). Handbook of adult development and learning. Oxford: Oxford University Press.

Johansson, H., Sjölander, P., \& Sojka, P. (1991). Fusimotor reflex profiles of individual triceps surae primary muscle spindle afferents assessed with multi-afferent recording technique. Journal de Physiologie, 85(1), 6-19.

Jolliffe I. T. (2002). Principal Component Analysis, Series: Springer series in statistics (2. ed.) New York: Springer.

King, P. M., Kitchener, K. S., Wood, P. K., \& Davison, M. L. (1989). Relationships across developmental lines: A longitudinal study of intellectual, moral and ego development. In M. L., Commons, J. D., Sinott, F. A., Richards, \& C. Armon (Eds.), Adult Development. Vol 1: Comparisons and applications of developmental models (pp. 57-72). New York: Praeger.

King, P. M., \& Kitchener, K. S. (2004). Reflective judgment: theory and research on the development of epistemic assumptions through adulthood, Educational Psychologist, 39(1), 5-18. doi: 10.1207/ s15326985ep3901_2

Loevinger, J. (Ed.). (1998). Technical foundations for measuring ego development. Mahwah, New Jersey: Lawrence Erlbaum.

Loevinger, J., \& Blasi, A. (1976). Ego development: Conceptions and theories (1. ed.). San Francisco: Jossey-Bass.
Loevinger, J., \& Hy, L. X. (1996). Measuring ego development (2. ed.). Mahwah, New Jersey: Lawrence Erlbaum Erlbaum.

Rosén, A. S. (1997). Measuring ego development by sentence completion in the Swedish context. In A. M. Carlsson, A. Cederström \& H. Janson (Eds.), Research in Rorschach and projective methods (pp. 85-92). Stockholm: Swedish Rorschach Society.

Sjölander, P. (2013). Hierarchical analyses of value systems based on evolutionary principles. Manuscript in preparation.

Skoe, E., \& von der Lippe, A. L. (2002). Ego development and the ethics of care and justice: The relations among them revisited. Journal of Personality, 70(4), 485-508. doi: 10.1111/1467-6494.05016

Stein, Z., \& Heikkinen, K. (2009). Models, metrics, and measurements in developmental psychology. Integral Review, 5(1), 4-24.

Torbert, W. R. (2004). Action inquiry: the secret of timely and transforming leadership. San Francisco, California: Berrett-Koehler.

Truluck, J. E., \& Courtenay, B. C. (2002). Ego development and the influence of gender, age, and educational levels among older adults. Educational Gerontology, 28(4), 325-336. doi: 10.1080/036012702753590433

Westenberg, M. P., Blasi, A., \& Cohn, L. D. (Eds.). (1998). Personality development: theoretical, empirical, and clinical investigations of Loevinger's conceptions of ego development Mahwah, New Jersey: Lawrence Erlbaum.

Westenberg, M. P., van Strien, S. D., \& Drewes, M. J. (2001). Revised description and measurement of ego development in early adolescence: an artifact of the written procedure? Journal of Early Adolescence, 21(4), 470-493.

\section{APPENDIX 1}

The questionnaire items

B5. How much responsibility do you feel different people and organizations have for the integration of refugees?

A great deal

» The government and Parliament

» All Swedish citizens

» Local authorities (e.g. municipality, county administrative board and county council)

» Non-profit organizations (e.g. sports associations, churches and the Red Cross)

» The refugees themselves

» National authorities (e.g. the Migration Board, the National Agency for Education and the Labor Market Board)

» My own

12

None at all 5

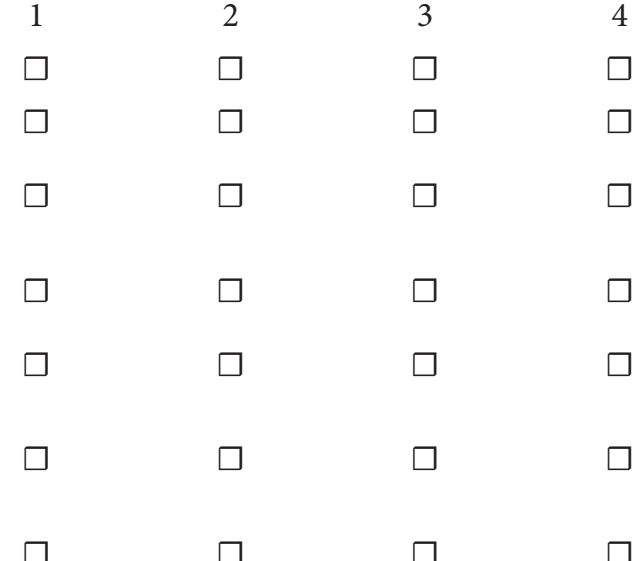


C1. What affinity do you feel with the following groups?

\begin{tabular}{|c|c|c|c|c|c|}
\hline & Close & & & & None \\
\hline & 1 & 2 & 3 & 4 & 5 \\
\hline » Europeans & $\square$ & $\square$ & $\square$ & $\square$ & $\square$ \\
\hline » My closest friends & $\square$ & $\square$ & $\square$ & $\square$ & $\square$ \\
\hline » The local inhabitants & $\square$ & $\square$ & $\square$ & $\square$ & $\square$ \\
\hline » All human beings & $\square$ & $\square$ & $\square$ & $\square$ & $\square$ \\
\hline » My family & $\square$ & $\square$ & $\square$ & $\square$ & $\square$ \\
\hline » Swedes & $\square$ & $\square$ & $\square$ & $\square$ & $\square$ \\
\hline » Groups with which I share interests or opinions & $\square$ & $\square$ & $\square$ & $\square$ & $\square$ \\
\hline » Refugees & $\square$ & $\square$ & $\square$ & $\square$ & $\square$ \\
\hline » Co-workers & $\square$ & $\square$ & $\square$ & $\square$ & $\square$ \\
\hline
\end{tabular}

\section{C2. What is most important to you?}

Rank the following statements where 1 is most important, 2 is second most important etc.

To contribute to developing other people in order to increase productivity and economic growth

That the social atmosphere provides security by accepting and appreciating me

To meet people with other values who develop my ability to critically scrutinize myself and the norms of society

That my surroundings satisfy my needs

That my surroundings value my expert competencies and occupational skills

Own formulation:

C3. What do you think makes a good boss?

Rank the following statements where 1 corresponds best, 2 corresponds second best etc.

A good boss...

Prioritizes mutual understanding and social atmosphere of togetherness

Is focused on achievements and economic growth

Is a natural authority who knows what is best for me

Understands the importance of expert competency in order to create maximum quality

Has long-term, social, humanistic and global goals and visions

Understands that all co-workers are individuals with different opportunities and limitations

Own formulation:

C4. How do you view laws and regulations?

Rank the following statements where 1 corresponds best, 2 corresponds second best etc.

Laws and regulations could always be questioned, except those based on fundamental principles (e.g. all humans' equal worth)

Laws and regulations are needed to obtain a fair society

Laws and regulations must take into consideration the conditions and needs of the individual

Laws and regulations make it more difficult for me to satisfy my needs

Laws and regulations should be followed without exception

Own formulation: 
C5. When you are not thinking about practical everyday problems (taking care of the household and children etc.), what do you mostly think about?

Rank the following statements where 1 is what you think about the most, 2 what you think about second most etc.

How mankind can be saved from global pollution, starvation and oppression

How my occupational skills can be improved or be put to better use

How to achieve a more tolerant society where all people and cultures are respected

How I can satisfy my needs in the easiest way possible

How to create more effective and productive companies and social structures

How I can be accepted and find security in my social surroundings

Own formulation: 